\title{
Signos, significados e práticas de manejo da crise em Centros de Atenção Psicossocial ${ }^{*}$
}

\author{
Mônica Lima ${ }^{1}$ \\ Vládia Jamile dos Santos Jucá ${ }^{2}$ \\ Mônica de Oliveira Nunes ${ }^{3}$ \\ Vitória Eugênia Ottoni ${ }^{4}$
}

LIMA, M. et al. Signs, meanings and practices of crisis management in psychosocial care centers. Interface - Comunic., Saude, Educ., v.16, n.41, p.423-34, abr./jun. 2012.

In this article, we discuss the meanings attributed by families and professionals to mental health crisis situations and their relationships with the technologies used in caring for users of psychosocial care centers in Bahia and Sergipe. We were inspired by the theoretical-methodological model of the system of signs, meanings and practices, using qualitative research techniques. We organized the data into two categories: signs and meanings of crises; and care strategies and difficulties. We observed that there was not much difference between professionals' and families' conceptions about crises, and that negative meanings supplanted positive meanings, thus evoking the concepts of subjection to disease, incapacity for rational social interaction and dangerousness of the patient. Two issues are important in managing crises: their unpredictability and their relationship to the individual's history. To overcome the management difficulties, investment in soft and soft-hard technologies based on durable bonds and intensification of care is necessary.

Keywords: Crisis. Biomedical Technology. Mental health. Psychosocial care center. System of signs, meanings and practices.
Neste artigo discutimos significados atribuídos pelos familiares e profissionais às situações de crise em saúde mental e suas relações com as tecnologias empregadas no cuidado de usuários de CAPS na Bahia e em Sergipe. Inspiramonos no modelo teórico-metodológico de Sistema de signos, significados e práticas, utilizando técnicas qualitativas de pesquisa. Organizamos os dados em duas categorias: os signos e significados de crise; as estratégias e as dificuldades no seu cuidado. Observamos que não há muita diferença entre as concepções de profissionais e familiares acerca da crise e que os significados negativos suplantam os positivos, evocando os conceitos de sujeição à doença, incapacidade de interação social racional e periculosidade do doente. Dois aspectos são importantes no manejo da crise: sua imprevisibilidade e sua inscrição na história da pessoa. Para contornar as dificuldades nesse manejo, é necessário investir nas tecnologias leve-duras e leves, pautadas em vínculos duradouros e na intensificação de cuidados.

Palavras-chave: Crise. Tecnologia de cuidado. Saúde mental. CAPS. Sistema de signos, significados e práticas.
- Elaborado com base em Nunes (2005) pesquisa aprovada pelo Comitê de Ética e financiada pelo

Ministério da Ciência e Tecnologia (MCT)/ Conselho Nacional de Desenvolvimento Científico e Tecnológico (CNPq), Edital MCTCNPq / MS-SCTIEDECIT/ CT - Saúde (07/2005)

${ }^{1-4}$ Núcleo Interdisciplinar em Saúde Mental, Instituto de Saúde

Coletiva, Universidade Federal da Bahia. Estrada de São Lázaro, 198

Federação. Salvador, BA, Brasil. 40.210-730 molije@hotmail.com 


\section{Introdução}

Está previsto que as atividades para os usuários desenvolvidas nos Centros de Atenção Psicossocial (CAPS) possam ser realizadas individualmente ou em grupo, que outras sejam destinadas às famílias destes usuários, ou, até mesmo, que sejam comunitárias. Assim, a partir da admissão de uma pessoa no CAPS, ela pode ter acesso a vários recursos terapêuticos, tais como: a) atendimento individual (prescrição de medicamentos, psicoterapia, orientação); b) atendimento em grupo (oficinas terapêuticas, oficinas expressivas, oficinas geradoras de renda, oficinas de alfabetização, oficinas culturais, grupos terapêuticos, atividades esportivas, atividades de suporte social, grupos de leitura e debate, grupos de confecção de jornal etc.); c) atendimento para a família (atendimento nuclear e a grupo de familiares, atendimento individualizado a familiares, visitas domiciliares, atividades de ensino, atividades de lazer com familiares); d) atividades comunitárias (atividades desenvolvidas em conjunto com associações de bairro e outras instituições existentes na comunidade); e) assembleias ou reuniões de organização do serviço (importante instrumento para o efetivo funcionamento dos CAPS como um lugar de convivência, que reúne técnicos, usuários, familiares e outros convidados, os quais, juntos, discutem, avaliam e propõem encaminhamentos para o serviço (Brasil, 2004). Além desses recursos terapêuticos, está indicado, no Manual do Ministério da Saúde "Saúde mental no SUS: os centros de atenção psicossocial", que, para as situações de crise, o acolhimento é fundamental, uma vez que se considera que uma pessoa em crise nem sempre terá condições de acompanhar as demais atividades organizadas no CAPS, precisando de um cuidado mais intensivo:

Os CAPS devem oferecer acolhimento diurno e, quando possível e necessário, noturno. Devem ter um ambiente terapêutico e acolhedor, que possa incluir pessoas em situação de crise, muito desestruturadas e que não consigam, naquele momento, acompanhar as atividades organizadas da unidade. O sucesso do acolhimento da crise é essencial para o cumprimento dos objetivos de um CAPS, que é de atender aos transtornos psíquicos graves e evitar as internações. (Brasil, 2004, p.17)

Nesta direção, considerando a desinstitucionalização como princípio maior da reforma psiquiátrica, no Brasil, e a consequente desospitalização como um dos pontos de partida para esse processo, atribuise ao CAPS o objetivo de atender aos transtornos psíquicos graves e evitar as internações, através da oferta de atividades terapêuticas, que não apenas a clássica farmacoterapia. Dar conta de usuários em crise, ou seja, não se esquivar do cuidado em situações de grave sofrimento psíquico, tornou-se o principal desafio desse modelo substitutivo.

Em artigo anterior, discutimos que os recursos terapêuticos - entre eles a recepção, grupos e oficinas (que denominamos, aqui, tecnologias) - "têm sido recriadas a partir de um movimento das equipes, que tentam os melhores caminhos, dentro das possibilidades, para fazerem os CAPS funcionarem" (Jucá, Lima, Nunes, 2008). Dedicamo-nos a entender tais recursos terapêuticos oferecidos em CAPS e pontuamos os desafios para o êxito do cuidado dos usuários, considerando que não há clareza entre os técnicos em relação aos motivos que os fazem realizar estas atividades, que faltam reflexões teóricas e avaliativas internas sobre a sua implementação no CAPS. Dentre os resultados, um dos domínios terapêuticos de maior vulnerabilidade apontado pelos informantes, tanto profissionais quanto familiares, foi aquele referente ao manejo da crise dos usuários.

Lidar com a crise em transtorno mental não tem sido e nunca foi uma tarefa simples. A complexidade que envolve tais situações justifica um investimento reflexivo sistemático para a compreensão de questões como estas: o que significa crise para aqueles envolvidos diretamente com o cuidado de pessoas com transtornos severos e graves, pessoas descritas como "em crise" ou que "dão crise" e/ou vivenciando situações/momentos de crise? O modo de significar e as práticas incorporadas levam à adoção de que estratégias para o contorno da crise nos CAPS (II, III ad e ia)?

Neste artigo, buscamos identificar alguns signos associados à crise, seus significados e as estratégias utilizadas nos CAPS para o cuidado dos usuários e seus familiares em situações ditas de crise. Antes de entrarmos em questões teórico-metodológicas, é importante apresentarmos o que estamos chamando de 
tecnologias de cuidado no contexto do nosso trabalho. Recorrendo à noção de virtual em Lévy (1996), filósofo de grandes contribuições na discussão sobre novas tecnologias e cultura contemporânea, podemos dizer que uma tecnologia deve ser pensada como algo que potencializa (ou virtualiza) as nossas ações. Nas palavras do próprio autor: " [...] o virtual é como um complexo problemático, o nó de tendências ou de forças que acompanha uma situação, um acontecimento, um objeto ou uma entidade qualquer, e que chama um processo de resolução: a atualização" (Lévy, 1996, p.16).

Apesar de o autor não ter nenhuma aproximação com o campo da saúde mental, utilizamos o conceito mais amplo por ele formulado para propormos que, nesse contexto específico, espera-se que as tecnologias produzam movimentos os quais devem implicar o reposicionamento dos sujeitos e, mesmo, o resgate ou a construção de laços sociais. No sentido de sinalizar que as tais atividades ou recursos terapêuticos previstos no processo de trabalho de um CAPS não garantem por si só a superação do desafio de lidar com pessoas em crise, uma vez que podem se configurar mais como tecnologia leve-dura do que como tecnologia leve, segundo o entendimento de Merhy. Ao nos aproximarmos do campo da saúde mental propriamente dito, encontramos, no referido autor, a discussão sobre tecnologias e a organização do processo de trabalho na saúde, diferenciando-as em tecnologias "duras" (aparelhos e ferramentas de trabalho) e em tecnologias denominadas "leve-duras" e "leves". As duas últimas são conceituadas, respectivamente, nos seguintes termos:

[define-se por leve-dura, porque] é leve ao ser um saber que as pessoas adquiriram e está inscrito na sua forma de pensar os casos de saúde e na maneira de organizar uma atuação sobre eles, mas é dura, na medida em que é um saber-fazer bem estruturado, bem organizado, bem protocolado, normalizável e normalizado. (Merhy, 1999, p.307)

Sendo leve, ela traduz: "momentos de possíveis cumplicidades, nos quais pode haver a produção de uma responsabilização em torno do problema que vai ser enfrentado, ou mesmo de momentos de confiabilidade e esperança, nos quais se produzem relações de vínculo e aceitação" (Merhy, 1999, p.308).

A tecnologia leve se remete então ao processo de relações inerentes a qualquer encontro entre usuário e profissional, pelo caráter relacional, que anuncia certa forma de agir entre os sujeitos implicados com a produção de saúde (Merhy, 1999). A tecnologia leve ganha relevo quando se "opera um jogo de expectativas e produções, criando-se intersubjetivamente alguns momentos interessantes como momentos de falas, escutas e interpretações" (Merhy, 1999, p.308).

Parafraseando Almeida et al. (2004, p.117), podemos afirmar que qualquer atividade que sirva para intermediar uma interlocução genuína entre cliente e profissional poderá resultar, ou não, em uma relação terapêutica.

Qualquer atividade, que seja eficaz como intermediação de um diálogo de um vínculo entre profissional e cliente, produzirá um relacionamento que pode ser terapêutico ou não. Existem atividades que se adéquam mais a um ou outro cliente, a partir da sua própria escolha, e que, por causa desse interesse pessoal, podem resultar em terapia. A relação é terapêutica, e não a atividade.

No mesmo sentido dessa problematização, encontramos em Csordas (2008) o pressuposto de que os indivíduos escolhem tais ou quais atividades por conta das suas afinidades e desejos, e que esta escolha contribui para tornar o procedimento terapêutico. A ênfase é colocada na relação estabelecida, e não na atividade em si; quem é terapêutica é a relação, e não a atividade.

Neste sentido, utilizamos o termo tecnologia para marcar a força do vínculo, do papel protagonista do usuário no seu cuidado, mas também do terapeuta na aposta e no acolhimento, em situações de crise ou não, do poder que relações autênticas podem ter para o cuidado em saúde mental. Partindo do pressuposto de que, no cuidado em saúde e também no manejo da crise, podemos identificar o uso dos três tipos de tecnologias empregadas pelos profissionais nos encontros cotidianos com usuários e familiares: tecnologias leves, tecnologias leve-duras e tecnologias duras.

O arranjo e o equilíbrio entre essas tecnologias conformam os diferentes tipos de modelos de atenção à saúde (Merhy, 1997), em nosso caso, esses arranjos podem ser mais ou menos inspirados nas premissas da desinstitucionalização. O campo do cuidado em saúde mental, que toma as necessidades subjetivas e 
sociais dos usuários como foco, e que possibilita a interação entre trabalhadores e usuários, é, portanto, o espaço privilegiado e cada vez mais evidente das tecnologias leves ou relacionais (Merhy, 1997).

O conceito de tecnologia leve fundamenta-se na importância da relação usuário-profissionais de saúde, usuário-familiar, usuário-usuário, ressaltando o vínculo como promotor de cuidado que pode propiciar um estado de bem-estar físico, psíquico e social, ou seja, um entendimento "vulgar" que temos de saúde; o que não quer dizer trivial, mas simplesmente comum, ao alcance de todos. $\mathrm{O}$ oposto seria a má saúde, enquanto restrição das margens de segurança orgânica, limitação do poder de tolerância e de compensação das agressões do meio ambiente (Canguilhem, 1990).

Este mesmo sentido pode ser encontrado na noção da clínica psicossocial das psicoses através da intensificação do cuidado. Radicalizar o uso da tecnologia leve em situação de crise é promover um intenso investimento humano, ou seja, tomar o cuidado como investimento humano promotor de efetivas mudanças no estilo, e quiçá nas condições, de vida do indivíduo, visando o sujeito. Como afirma Oliveira e Mota (2007, p.17), investir "em prol das necessidades do sujeito que está em crise ou deste sujeito psicótico no mundo, e ver o que a gente pode fazer, através deste investimento, para produzir uma mudança em sua qualidade de vida, em sua posição no mundo, em sua liberdade".

Recepcionar e acolher a pessoa em crise remete à noção de tecnologia como correlata de investimento humano que requer intensificação de cuidado. Schmidt e Figueiredo (2009, p.137) nos advertem para $\mathrm{o}$ ato de acolhimento:

acolher é um processo que depende não só da estrutura ou de aspectos físicos do acesso, mas dos recursos clínicos da equipe, como atender, escutar, avaliar e discriminar as demandas. O acolhimento exige, por um lado, uma ação imediata (urgência) e, por outro, um intervalo de tempo para a resposta (traçar a conduta).

Nesse intervalo, podemos inscrever processos que envolvem "o tempo do sujeito", mas, também, "o tempo do território", entendendo-o como o lugar da duração (Leal, Delgado, 2007), onde as relações se tecem e as dinâmicas sociais são desencadeadas.

\section{Considerações teórico-metodológicas}

O texto aqui apresentado traz um recorte sobre as tecnologias para o cuidado da crise de usuários em dispositivos substitutivos de cuidado em saúde mental, particularmente em centros de atenção psicossocial (CAPS). A pesquisa, financiada pelo CNPq, "Articulando experiências, produzindo sujeitos e incluindo cidadãos: um estudo sobre as novas formas de cuidado em saúde mental na Bahia e em Sergipe, Brasil" (Nunes et al., 2005), da qual este texto se origina, conta com dois momentos fundamentais. A primeira fase do trabalho foi denominada semi-intensiva (2006-2007). O objetivo principal desse momento foi conhecer, de modo mais abrangente, o funcionamento dos serviços, as conquistas realizadas e as principais dificuldades vivenciadas pelas equipes. Essa primeira fase foi desenvolvida em três semanas, nas quais, além das entrevistas e grupos focais, a equipe de pesquisadores realizava um período de observação sistemática, sobretudo acerca das atividades desenvolvidas nos CAPS.

Em termos de técnicas empregadas, realizamos: entrevistas com gestores (Secretários de Saúde), Coordenadores dos CAPS, entrevistas com usuários e grupos focais com profissionais e com familiares. Nesta pesquisa foram estudados 11 CAPS, sendo sete na Bahia e quatro em Sergipe. Em Aracaju, foram estudados diferentes CAPS correspondentes a cada uma das seguintes modalidades: tipo I, tipo III, infanto-juvenil e CAPSad, para dependentes de álcool e de outras drogas. Na Bahia, todas as modalidades foram estudadas, à exceção do CAPS III, por nos ter sido dificultada a investigação nesse serviço tanto por parte da Coordenadora do mesmo quanto da Secretária de Saúde de um dos municípios escolhidos para estudo. Tentamos ainda contemplar, na Bahia, uma certa representatividade regional, não no sentido epidemiológico do termo, mas na perspectiva de integrarmos, em nosso grupo de pesquisa, CAPS situados em macrorregiões distintas. Buscávamos com isso obter alguma 
diferenciação, sobretudo, em termos culturais e demográficos, tendo sido observadas também distinções sociais e econômicas.

A principal característica da segunda etapa da pesquisa (2007-2008) foi promover um aprofundamento do trabalho de investigação em três CAPS previamente selecionados a partir de critérios tais como: tempo superior a um ano de funcionamento, presença de uma equipe atuante, disponibilidade do serviço em receber os pesquisadores, e ser perto da capital. Nessa fase, a pesquisa adquiriu uma configuração etnográfica, através da qual os pesquisadores buscaram uma maior imersão nos serviços, acompanhando as atividades através de observação participante e relatando-as em diários de campo, bem como realizando entrevistas com usuários, profissionais e membros das comunidades nas quais os serviços se encontravam localizados.

Utilizamos um conjunto de estratégias de coletas e acessamos uma diversidade de entrevistados a fim de conhecermos as concepções e as experiências concretas de todos os sujeitos envolvidos no CAPS acerca do sofrimento mental e da sua relação com a inserção social dos usuários e a construção da cidadania, levando em conta as diretrizes político-clínicas prescritas para este tipo de dispositivo de saúde mental.

O modelo metodológico de Sistema de Signos, Significados e Práticas - S/SSP (Almeida-Filho, Coelho, Peres, 1999, Bibeau, 1992) foi o que nos inspirou na elaboração deste artigo, recorte da extensa pesquisa acima referida, sem contudo ter seguido, canonicamente, toda sua complexa metodologia. O S/SSP foi desenvolvido considerando-se a perspectiva de uma hermenêutica antropológica que se dispõe a articular os contextos micro e macrossociais, propondo um método de trabalho que parte das experiências subjetivas e trajetórias singulares das pessoas em situações concretas (Bibeau, 1992). O S/SSP é constituído de três níveis para a abordagem de um problema durante uma investigação: o factual, o narrativo e o interpretativo (Bibeau, 1992).

No primeiro nível, factual, parte-se da ideia de que é preciso levantar fatos, eventos e ações concretas significativas para os sujeitos da pesquisa (Bibeau, 1992). O níve/ narrativo diz respeito à coleta inicial de relatos espontâneos sobre a problemática e a identificação dos interlocutores-chave. Em um segundo momento, mais sistemático, refere-se à reconstrução propriamente dita das experiências dos interlocutores que lidam cotidianamente com a problemática. Neste particular, é prudente ressaltar que as narrativas são as principais unidades de análise da proposta, e não os casos propriamente ditos, marcando um outro tipo de delineamento de pesquisa, que não o de estudo de caso advindo da clínica médica e psicológica ou da corrente sociológica (Bibeau, 1992). O nível interpretativo implica considerar as interpretações dos interlocutores enquanto uma interpretação nativa, à qual o pesquisador não pode se limitar. Consideramos que a hermenêutica antropológica requer a passagem da mera descrição dos fatos e modelos explicativos nativos para a elaboração de uma interpretação, ou seja, um trabalho cooperativo analítico que propicie a emergência dos sentidos os quais podem escapar aos próprios atores sociais (Bibeau, 1992).

No plano de análise do nosso estudo, para levar a cabo o nível interpretativo, utilizamos o seguinte procedimento para interpretação das narrativas: a) a identificação e agrupamento dos termos utilizados pelos próprios entrevistados; b) a construção de categorias analíticas, considerando os significados que Ihes são atribuídos, já que incentivamos relatos de situações concretas de trabalho, desde as estratégias de acompanhamento do cuidado e de situações de crise até as descrições da organização do processo laboral.

\section{Signos, significados e estratégias de cuidado da crise}

Nesta seção, traçaremos a análise das narrativas dos nossos sujeitos em diferentes CAPS, a partir de duas categorias: 1) os signos e significados de crise; 2) as estratégias de cuidado da crise e as dificuldades para a organização do processo de trabalho em saúde mental.

O que seria a crise na sua etimologia, na sua raiz? Recorrendo-se ao sânscrito, matriz das línguas ocidentais, encontramos o kri como origem da crise, significando limpar, desembaraçar e purificar, bem como da crítica, "processo pelo qual nos damos conta dos pressupostos, dos contextos, do alcance e dos limites" de fenômenos (Boff, 2002) 
Hipócrates e sua escola se apropriam da crise para significar o momento de avaliação dos sintomas do padecente. Em Latim, o significado da crisis vai na mesma direção, caracterizando a fase em que se decide o curso da doença, em direção à cura ou à morte (Machado, 2003.) No latim, o termo crise tem a mesma equivalência da palavra vento. Indica, assim, um estágio de alternância, no qual, uma vez transcorrido, diferencia-se do que costumava ser. Não existe possibilidade de retorno aos antigos padrões; enfim, o termo crise significa modo de decisão que pode tornar a vida melhor ou pior. Esta acepção da língua portuguesa remete-se à noção de normatividade desenvolvida por Canguilhem (2010), quando o autor define que a doença instaura uma nova normatividade diferente daquela da saúde. Trata-se de um termo polissêmico, mas que nos remete, invariavelmente, à noção de um estado de movimento e de mudança.

No entanto, quando estamos falando de pessoa em crise, que entra em crise, pessoas com transtornos mentais graves e severos, com ou sem abuso de álcool e outras drogas, observamos particularidades que remetem às representações sociais negativas associadas à loucura e as consequências daí decorrentes. Estamos de acordo com a consideração de que a "crise é um arranjo providencial que se tem à disposição quando todos os recursos psíquicos do sujeito já foram utilizados. A crise é ponto de corte. Ela representa a experiência de inconstância subjetiva que se coloca para o sujeito quando este é colocado em questão" (Vidal, Braga, Sodré, 2007, p.155).

Estes autores destacam que há sempre um grau de imprevisibilidade na crise, nem sempre é possível identificar algum evento externo, concreto e objetivo como desencadeador, e nem todos os sujeitos respondem do mesmo modo frente a eventos cotidianos, há sempre um efeito subjetivo singular. Fontenelle (2010), no estudo sobre crise em um CAPS no Vale do São Francisco, se dedicou a compreender os antecedentes e motivadores. Esta autora encontrou diferenças entre os profissionais da equipe multiprofissional estudada quanto a estes aspectos, embora tenha concluído que parâmetros prévios generalizáveis são cada vez menos úteis para a organização do cuidado em relação à importância de se conhecer a história de vida de cada um desses sujeitos. Ao mesmo tempo, em uma perspectiva mais sociológica, não podemos deixar de buscar analisadores de crise mais associados a determinantes sociais e econômicos, tais como aqueles evidenciados pelo trabalho de Béhague (2009), no seu estudo com jovens em terapia, na cidade de Pelotas, com diagnósticos de transtornos de conduta.

\section{Signos e significados da crise}

Entre os signos utilizados pelos entrevistados quando relatam situações/momentos de crises e os significados construídos em torno dessa problemática, podemos organizá-los em dois sentidos diferentes e complementares: a) significados que se direcionam à descrição da pessoa em si (do usuário/louco) e b) e aqueles que se remetem às consequências decorrentes do seu estado de alteração para ela e para os outros. Não há muita diferença nas concepções de profissionais e familiares. No caso dos profissionais que estudamos, os dados se aproximam dos achados de Fontenelle $(2010$, p.37) de que a crise se relacionaria

à interpretação de sinais identificados nos comportamentos dos usuários, em especial aqueles tidos como não habituais. Neste sentido, em muitos casos, esses sinais podem ser percebidos mais pela quebra de um padrão de comportamento do sujeito do que propriamente pelo comportamento em si, onde a frequência ou constância do comportamento entram no jogo das interpretações do profissional sobre a crise.

Para os nossos entrevistados, as pessoas que entram em crise, em alguns momentos/situações, tornam-se "perigosas, violentas, agressivas, brabas, despertam medo, incomodam os outros, quebram e destroem as coisas, gritam", termos utilizados pelos entrevistados. No entanto, são consideradas como pessoas em alto nível de sofrimento, porque estão angustiadas, ouvem vozes de comando, necessitam de vigilância contínua, estão confusas, colocam-se em risco de morte, desestruturam as famílias. No caso de usuários de CAPS-ad, existe uma tendência, por parte dos entrevistados, de considerá-los como doentes, e não viciados, numa tentativa de atenuar o que excede de estigma associado ao uso de 
drogas, sobretudo ilícitas. Em todos os casos, tornam-se uma ameaça pessoal e social, que exige dedicação quase exclusiva por parte dos cuidadores, como se pode perceber em relatos de profissionais que participaram do grupo focal em um CAPS II de Aracaju, SE. Um deles transcreve-se a seguir:

"crises a partir de uma necessidade de vigilância, sendo muito exigente enquanto forma de cuidado, gerando um impacto sobre a vida de todos, preocupações e uma dedicação quase exclusiva à pessoa doente".

É importante ressaltar que há uma sutil diferença no uso do termo crise quando consideramos o tipo de CAPS: quando ele é um CAPSad, o termo é menos utilizado pelos profissionais do que em CAPS II e III. Apesar disso, todos compartilham que o CAPS, independente do tipo, deve responder às exigências do cuidado de pessoas com transtornos graves e severos. Dentro da especificidade de um dos CAPSad em Salvador-BA, enquanto um serviço de assistência a pessoas com transtornos mentais severos e graves decorrentes do consumo de álcool e outras drogas, havia uma tentativa de distinguir situações em que a problemática em torno do consumo do álcool e outras drogas representava a principal questão a ser trabalhada. Nesta perspectiva, a equipe deste CAPSad vinha optando pelo encaminhamento de usuários com diagnóstico de psicose para os CAPS II e CAPSia, uma vez que, nesses casos, entendiam o consumo de álcool e outras drogas como questão secundária.

Ainda no caso dos usuários de CAPSad, podemos ter relatos de familiares que acompanham seus parentes em momentos de sofrimento intenso (quando estão "drogados" em vez de estarem em "crise"). Nesses casos, não utilizam o termo crise, mas remetem essas expressões a situações de sofrimento, onde o contato com o CAPSad pode gerar a ressignificação do problema do seu parente, deixando a questão de ser vista como um vício, e passando a ser entendida como um problema de saúde, como familiares relataram no grupo focal no CAPS II em Salvador, BA:

"Tem muitas mães que sofrem muito... porque eu cuidei tanto sem conhecer o que era a droga, a bebida alcoólica, estudei tanto sobre ela... por meus filhos serem drogados, que eu esqueci que o álcool é uma droga também. Então ele não usa droga, tipo de droga química nenhuma, mas o álcool é uma droga que persegue muito e muitas mães que moram num bairro pobre, muitas vezes ela sofre muito, mas não acredita que exista o CAPS".

Esses signos e significados associados pelos entrevistados sobre a crise nos conduzem a compartilhar com Oliveira (2007, p.52) que, em torno da crise, giram "aqueles aspectos que causam alguma ordem de estranheza e uma perturbação social importante". Embora, entre os entrevistados, os significados negativos suplantem em muito os positivos sobre a crise, ela adquire uma temporalidade, no sentido de que, fora da crise, o sujeito é capaz de negociar com alguns parâmetros de normalidade, não estando totalmente dominado pela doença, apresentando uma parte de si que é capaz de interpretar sua situação de doença, interagir com as pessoas ao seu redor e agir movido por uma motivação consciente. O tema da ruptura e o limite entre a normalidade e o patológico foram muito bem definidos por Canguilhem (2010, p.135), como destacado na citação a seguir:

A fronteira entre o normal e o patológico é imprecisa para diversos indivíduos considerados simultaneamente, mas é perfeitamente precisa para um único e mesmo indivíduo considerado sucessivamente. Aquilo que é normal, apesar se ser normativo em determinadas condições, pode se tornar patológico em outra situação, se permanecer inalterado.

Em um dos CAPS II de Aracaju-SE, encontramos uma associação de que situações de crise, tomadas como categoria êmica de "puro surto", quando acolhidas em seu estado radical, possam gerar "construções belíssimas [...] em plena crise" e remeter à noção de que tais "pessoas têm algo mais além da doença, têm saúde também". Crise como potência criativa, aqui construída a partir da descrição da "Oficina de crise", realizada no referido CAPS II, que mantém o usuário em crise sob acompanhamento intensivo, tendo como premissa só recorrer à internação como última alternativa. 
Percebemos que não é uma decisão simples recorrer à internação de um usuário em situação de crise, o que pode gerar mal-estar na equipe que o acompanha quando decidem por esta alternativa. Como destacam Schmidt e Figueiredo (2009), falando sobre a realidade de outra equipe de CAPS no Rio de Janeiro, a internação é um recurso para lidar com a crise, mas depende da justificativa que sustenta a decisão. É percebida como fracasso, pela equipe, quando é utilizada porque não há disposição do serviço para lidar com a crise, mas pode ser usada como último recurso para lidar com as situações de crise, porque, entre os seus entrevistados, há a percepção de que, às vezes, internar é necessário. A internação é aceitável desde que a equipe possa ter acesso ao usuário durante todo este momento, que deve ser o mais curto possível, para possibilitar o retorno do usuário ao CAPS.

\section{Estratégias de cuidado e dificuldades para lidar com situações de crise}

Esses estados de crise exigem um cuidado intenso e intensivo por parte de profissionais e familiares. Entre as estratégias de manejo da crise podemos citar: a) acolhimento diurno e noturno; b) observação continuada e contínua; c) atenção domiciliar (visitas domiciliares); d) responsabilização pelo cuidado medicamentoso; e) presença do psiquiatra na equipe para garantir o êxito da prescrição; f) negociação e apoio concreto ao familiar para que o internamento seja o último recurso utilizado; g) elaboração de cartilha com orientação sobre como lidar com a crise de pessoas com transtornos, para profissionais não especializados em saúde mental e para familiares; h) implantação das "Oficinas de crise" nos CAPS; i) estabelecimento de limites para os usuários através de regras de convivência para evitar o uso de álcool e outras drogas no CAPS; e, como sugerem os parentes, j) na perspectiva dos familiares, não podem faltar carinho, compreensão e fé.

Em que medida tais estratégias, identificadas nas narrativas dos entrevistados, tendem a "construir em torno da pessoa um ponto de referência real em direção ao qual esta possa orientar as suas ações e seus comportamentos" em momento de maior fragilidade? (Dell'acqua, Mezzina, 2005, p.173). A "tomada de responsabilidade" como meio de lidar com as situações de crise, para além da emergência, reforça a "responsabilidade do serviço sobre a saúde mental de toda a área territorial de referência e pressupõe um papel ativo na sua promoção". Trata-se de uma modalidade de relação institucional que assume ativamente as demandas relativas às situações de miséria, de distúrbio e de conflito (Dell'acqua, Mezzina, 2005, p.175).

Há muitos impedimentos na aproximação e entendimento desse objetivo, definido como "tomada de responsabilidade", entre os entrevistados. Em relação às dificuldades para o manejo de crises nos CAPS, identificamos: a) falta de preparo dos profissionais para lidar com a crise; b) falta de retaguarda de outros equipamentos de saúde para auxiliar o CAPS; c) resistência e rejeição em relação aos usuários em crise nos equipamentos gerais de saúde (os não especializados em saúde mental), mesmo quando acompanhados pelo profissional do CAPS; d) insuficiência da capacidade institucional para o atendimento de demanda por psicoterapia e de atenção à crise ou situação de emergência; e) dificuldades materiais, sociais e/ou afetivas, por parte das famílias, de suportarem a crise dos seus membros.

No manejo de crises, o acolhimento noturno é visto como imprescindível pelos profissionais e familiares. O desafio posto às redes de saúde, que não contam com CAPS III e sofrem com a resistência e recusa de usuários com transtornos mentais, por parte de profissionais em equipamentos de saúde não especializados em saúde mental, resulta em outras estratégias, tais como: a) controlar e reduzir o tempo da internação, seja em hospitais gerais seja em psiquiátricos; b) estabelecer a relação com o Serviço de Atendimento Médico de Urgência (SAMU) e a emergência como alternativas de cuidado; c) garantir unidade de cuidado intensivo em psiquiatria ("UTI Humanizada do ponto de vista psiquiátrico").

Os desafios destacados acima - relativos à ausência total da responsabilização do cuidado de usuários com transtornos mentais em serviços de saúde "não especializados em saúde mental" e ao descaso institucional com a Política Nacional de Saúde Mental, que deixam os CAPS sem a alternativa de acolhimento noturno e sem procedimentos técnicos de urgência/emergência (desintoxicação, por 
exemplo) - contribuem com a ideia, disseminada entre alguns familiares, de que as "crises brabas" só são resolvidas no hospital psiquiátrico. Para provar o contrário aos familiares e a certos profissionais de saúde não especializados em saúde mental, algumas equipes de CAPS, muitas vezes, recorrem a iniciativas extremamente pessoais, como pegar o próprio carro para levar um usuário para a emergência, ou omitir da equipe do SAMU que se tratam de pessoas com transtornos mentais, por exemplo.

Os significados construídos por profissionais e familiares no cuidado à crise de pessoas com transtornos mentais nos fazem compartilhar, com Oliveira (2007, p.16), que "lidar com a crise não se trata de um lugar, de uma instituição, mas de uma atitude clínica compatível com as exigências de quem vai substituir o hospital psiquiátrico", e tudo mais que advém como corolário desta nova atitude e o que isso pode significar para a mudança dos modos de cuidados em saúde mental vigentes.

Há, ainda, uma noção que aparece entre os profissionais de um dos CAPSi de Salvador, BA, para o manejo das crises: os usuários, quando realmente acompanhados, ou seja, quando se tornam conhecidos, pela equipe de profissionais, são mais beneficiados pelas estratégias descritas acima, as quais prezam pelo emprego das tecnologias leves e que implicam o investimento humano entre usuário e profissional. Isto fica claro nos seguintes relatos provenientes do grupo focal:

\footnotetext{
“Uma coisa interessante também é que os pacientes já conhecidos, já usuários há algum tempo, os profissionais de referência deles às vezes já dão conta de alguma forma. A gente observa situações assim: os pacientes novos em geral que são encaminhados pra emergência têm um quadro de agitação e precisam de medicação. Mas outros casos a gente já consegue controlar sem medicação, pelos vínculos... mas, os que já são da casa. Os que já têm um tempo conosco. Como a gente tem vivenciado uma coisa que se prende até a nós psiquiatras... porque a gente lida muito com a medicação, aquele paciente sair daquele quadro sem medicação".
}

"É bem nesse ponto, como trabalhar com a crise. Acolher a crise, poder escutar que crise é essa, crise psiquiátrica, crise do sujeito... poder escutar o sujeito e aproveitar a crise como sendo a forma que ele tem de se manifestar, ele conseguiu colocar no sintoma aquele sofrimento todo que ele tava, então aproveitar... fazer uma escuta... e acolher aquilo, antes de você calar com a medicação".

Certamente, considerando as experiências relatadas pelos profissionais de CAPS destacadas acima, podemos perceber que os mesmos apostam na potência vincular, ou seja, na tecnologia-leve (onde aparece, em relevo, o protagonismo do usuário e do profissional de saúde) mais do que na tecnologia leve-dura (prescrição de psicofármacos). O vínculo bem estabelecido e a escuta do sujeito possibilitam a estabilização do quadro crítico, da crise, sem o uso mandatório da medicação.

Segundo a perspectiva dos autores citados aqui, o cuidado do sujeito (em crise ou não) conjuga: o reconhecimento da complexidade do problema, a imprevisibilidade e a singularidade que envolvem a crise com a capacidade operativa dos serviços de saúde, e, portanto, dos profissionais de saúde como operadores aptos e competentes para gerarem respostas compatíveis com tais situações. Como destacam os autores na citação abaixo, se fazem necessárias: "a manutenção dos vínculos com o seu ambiente, a individuação dos nexos entre a crise e sua história, [a] reconstrução e redefinição das relações com as pessoas significativas, a construção de novas redes de relação" (Dell'acqua, Mezzina, 2005, p.191).

Portanto, há diferença entre cuidar daqueles que aparecem pela primeira vez para uma equipe, seja no CAPS seja em outros serviços de emergência, e aqueles que são acompanhados, ou seja, quando já houve alguma oportunidade e possibilidade de contato prévio para o estabelecimento de um vínculo genuíno. Isso fortalece a ideia de se compreender a crise como um acontecimento em uma sequência histórica, devendo-se desenvolver recursos e estratégias de se apreender o sujeito na sua historicidade. 


\section{Considerações finais}

Tenderíamos a visualizar um sistema de atenção psicossocial como uma configuração de dispositivos tecnológicos suficientemente flexíveis e articulados que pudessem se adaptar às necessidades que surgem do interior das histórias de sofrimento, especialmente aquelas que surgem na emergência das crises, de modo a dar uma resposta rápida para contê-lo. Por vezes, pode ser paradoxal designar, de leves, tecnologias que lidam com dores tão pesadas, como as que surgem em condições psíquicas extremas, como aquelas presenciadas em situações de crise. No entanto, se completarmos o pensamento de Merhy, talvez apontemos para a "insustentável leveza do ser" tantas vezes revelada na fragilidade de alguém que ameaça, grita, se debate ou se fere por estar tomado por um medo sem contornos ou por uma realidade que o tiraniza.

A ideia que tentamos veicular é exatamente aquela de que, por mais contingente que seja a vida e suas expressões, inclusive das suas dores, e por mais aterrorizadoras que sejam as condições encontradas nas crises (por todos aqueles que as vivem - usuários, familiares e técnicos), apenas relações vinculares sólidas e estratégias de cuidado consistentes, seguras e corajosas são capazes de conter acontecimentos que indicam uma situação de desordem, de desestruturação e de caos. Tendo em vista a pluralidade de significados, formas de expressão e domínios da existência envolvidos nessas situações, essas estratégias vinculares só podem ser desenhadas em arquiteturas relacionais complexas que ponham em contato sujeitos, disciplinas, saberes, fazeres e afetos de modo a que uma auto e inter-reflexividade seja viável.

Rotelli et al. (2001, p.45) nos advertem, no âmbito mais operacional da desinstitucionalização, para a necessidade de investirmos recursos em pessoas (operadores em saúde mental), mais do que nas instituições; para se reforçar a profissionalização que se explica mais em relação à "capacidade de escolher, utilizar e combinar uma ampla variedade de modalidades e de recursos de intervenção"; dar ênfase ao trabalho em equipe; instalar autoavaliação (no interior do trabalho cooperativo); formar profissionais para e no trabalho operativo nos centros; reforçar o paradigma do "case management".

Sabe-se do intenso corpo a corpo que esse paradigma pressupõe, uma vez que se ocupar de sujeitos com condições psíquicas de intensa gravidade, especialmente em situações onde essas condições expõem sua maior intensidade, exige uma concretude e uma materialidade que são inviabilizadas por situações de precariedade de vínculos empregatícios, de rotatividade de profissionais, de insuficiência de recursos e de ausência de estruturas adequadas de atendimento. Em sendo as crises imprevisíveis, o tempo para acolhê-las deve ser permanente. Ao mesmo tempo, seguindo os doentes em uma temporalidade capaz de produzir uma história e permitindo-Ihes participar mais ativamente no manejo das crises, aumenta-se a chance de torná-las "menos necessárias" e se ganha na potencialização de mecanismos de gestão coletiva das mesmas (incluindo as famílias e os usuários nesse processo).

\section{Colaboradores}

As autoras trabalharam juntas em todas as etapas de produção do manuscrito, sendo a ordem de autoria e coautoria previamente definida por critérios estabelecidos pelos próprios membros do Núcleo Interdisciplinar em Saúde Mental (NISAM/ISC/UFBA). 


\section{Referências}

ALMEIDA, A. et al. Oficinas em saúde mental: relato de experiências em Quixadá e Sobral. In: COSTA, C.; FIGUEIREDO, A. (Orgs.). Oficinas terapêuticas em saúde mental. Rio de Janeiro: Contra Capa Livraria, 2004. p.117-34.

ALMEIDA-FILHO, N.; COELHO, M.T; PERES, M.F. Conceito de saúde mental. Rev. USP n.43, p.100-25, 1999.

BÉHAGUE, D.P. Psychiatry and politics in Pelotas, Brazil: the equivocal quality of conduct disorder and related diagnoses. Med. Anthropol. Q., v.23, n.4, p.455-82, 2009.

BIBEAU, G. ?Hay una enfermedad en las americas? Otro camino de la antropologia médica para nuestro tiempo. In: CONGRESO DE ANTROPOLOGIA En COLOMBIA, 6. 1992, Santa Fé de Bogotá. Anais... Santa Fé de Bogotá: Universidad de los Andes, 1992. Digitalizado.

BOFF, L. Crise: oportunidade de crescimento. Campinas: Verus, 2002.

BRASIL. Ministério da Saúde. Secretaria de Atenção à Saúde. Departamento de Ações Programáticas Estratégicas. Saúde mental no SUS: os Centros de Atenção Psicossocial. Brasília: Ministério da Saúde, 2004.

CANGUILHEM, G. La santé: concept vulgaire \& question philosophique. Toulouse: Sables, 1990

O normal e o patológico. Rio de Janeiro: Forense Universitária, 2010.

COSTA, M.S. Construções em torno da crise: saberes e práticas na atenção em saúde mental e produção de subjetividades. Arch. Bras. Psicol., v.59, n.1, p. 94-108, 2007. Disponível em: <http://seer.psicologia.ufrj.br/seer/lab19/ojs/viewarticle.php?id=58 \&layout=abstract $>$. Acesso em: 13 ago. 2010.

CSORDAS, T. Corpo/Significado/Cura. Porto Alegre: Editora UFRGS, 2008.

DELL'ACQUA, G.; MEZZINA, R. Resposta à crise: estratégia e intencionalidade da intervenção no serviço psiquiátrico territorial. In: AMARANTE, P.D.C. (Org.). Archivos de saúde mental e atenção psicossocial. Rio de Janeiro: Nau, 2005. v.2, p.161-94.

FERIGATO, S.; ONOKO-CAMPOS, R.; BALLARIN, M.L. O atendimento à crise em saúde mental: ampliando conceitos. Rev. Psicol. Unesp, v.6, n.1, p.31-44, 2007. Disponível em: <http://www.fcm.unicamp.br/laboratorios/saude_mental/artigos/atendimento Crise_saude_mental.pdf $>$. Acesso em: 8 ago. 2010.

FONTENELLE, A.S. Sujeitos em crise: estratégias de intervenção de profissionais em Centro de Atenção Psicossocial - CAPS - II. 2010. Dissertação (Mestrado) - Programa de Pós-Graduação em Psicologia, Universidade Federal do Espírito Santo, Vitória. 2010.

JARDIM, K.; DIMENSTEIN, M. Risco e crise: pensando os pilares da urgência psiquiátrica. Psicol. Rev., v.13, n.1, p.169-90, 2007. Disponível em: <http:// periodicos.pucminas.br/index.php/psicologiaemrevista/article/view/267/276>. Acesso em: 08 ago. 2010.

JUCÁ, V.; LIMA, M.; NUNES, M. A re(invenção) de tecnologias no contexto de centros de atenção psicossocial: recepção e atividades grupais. Rev. Saude Mental Subj., v.6, n.11, p.125-44, 2008.

LEAL, E.; DELGADO, P.G.G. Clínica e cotidiano: o CAPS como dispositivo de desinstitucionalização. In: PINHEIRO, R. et al. (Orgs.). Desinstitucionalização na saúde mental: contribuições para estudos avaliativos. Rio de Janeiro: Cepesc; IMS/LAPPIS; Abrasco, 2007. p.137-54.

LÉVY, P. “O que é o virtual?". São Paulo: Editora 34, 1996. 
MACHADO, J.P. Dicionário etimológico da língua portuguesa. Lisboa: Livros Horizonte, 2003.

MERHY, E. O ato de governar as tensões constitutivas do agir em saúde como desafio permanente de algumas estratégias gerenciais. Cienc. Saude Colet., v.4, n.2, p.305-14, 1999. Disponível em: <www.scielo.br>. Acesso em: 4 nov. 07.

Em busca do tempo perdido: a micropolítica do trabalho vivo em saúde. In: $\overline{M E R H Y}$, E.E.; ONOCKO, R. (Orgs.). Agir em saúde: um desafio para o público. São Paulo: Hucitec, 1997. p.71-102.

NUNES, M. Articulando experiências, produzindo sujeitos e incluindo cidadãos: um estudo sobre as novas formas de cuidado em saúde mental na Bahia e em Sergipe, Brasil. 2005. (Projeto de pesquisa). Digitalizado.

NUNES, M. et al. Articulando experiências, produzindo sujeitos e incluindo cidadãos: um estudo sobre as novas formas de cuidado em saúde mental na Bahia e em Sergipe, Brasil. 2005 (Projeto de pesquisa submetido e aceito pelo CNPq). Digitalizado.

OLIVEIRA, M. Psicose e ressonâncias sociais. In: SILVA, M. V. O.(Org.) . IN-tensa/EXtensa: a clínica psicossocial das psicoses. Salvador: LEV - Laboratório de Estudos Vinculares / UFBA, 2007. p.52-69.

OLIVEIRA, M.; MOTA, E. Entrevista com Eduardo Mota e Marcus Vinícius Oliveira, supervisores do Programa de Intensificação de Cuidados a Pacientes Psicóticos. In: SILVA, M. V. O.(Org.). IN-tensa/EX-tensa: a clínica psicossocial das psicoses. Salvador: LEV - Laboratório de Estudos Vinculares/UFBA, 2007. p.15-36.

SCHMIDT, M.; FIGUEIREDO, A. Acesso, acolhimento e acompanhamento: três desafios para o cotidiano da clínica em saúde mental. Rev. Latinoam. Psicopat. Fund., v.12, n.1, p.130-40, 2009.

VIDAL, F.B.; BRAGA, A.C.S.; SODRÉ, A.R.O.M. A abordagem da crise na psicose. In: SILVA, M. V. O.(Org.). IN-tensa/EX-tensa: a clínica psicossocial das psicoses. Salvador: LEV - Laboratório de Estudos Vinculares/UFBA, 2007. p.151-68.

LIMA, M. et al. Signos, significados y prácticas en situaciones de crisis en los Centros de Atención Psico-social. Interface - Comunic., Saude, Educ., v.16, n.41, p.423-34, abr./jun. 2012.

Discutimos los significados atribuídos por los familiares y profesionales a situaciones de crisis en salud mental y sus relaciones con las tecnologías empleadas en el cuidado de usuarios de CAPS (Centros de Atención Psicosocial) en Sergipe, Brasil. Nos inspiramos en el modelo de Sistema de signos, significados y prácticas. Organizamos los datos en dos categorías: los signos y significados de crisis; las estrategias y dificultades en su cuidado. No hay mucha diferencia entre las concepciones de profesionales y familiares acerca de la crisis y los significados negativos suplantan los positivos, evocando los conceptos de sujeción a la enfermedad, incapacidad de interacción social racional y peligrosidad del enfermo. Dos aspectos son importantes en el manejo de la crisis: su imprevisibilidad y su inscripción en la historia de la persona. Es necesario investir en las tecnologías blanda-duras y blandas, pautadas en vínculos duraderos y en la intensificación de los cuidados.

Palabras clave: Crisis. Tecnología biomedica. Salud Mental. Centros de Atención Psicosocial. Sistema de signos, significados y prácticas. 